\title{
Investigation of the underwater noise produced by ships by means of intensity method
}

\author{
Eugeniusz Kozaczka, Prof. \\ Gdansk University of Technology \\ Jacek Domagalski, Ph. D. \\ Ignacy Gloza, Ph. D. \\ Naval Academy of Gdynia
}

\begin{abstract}
This paper presents results of research on spectral structure of underwater noise acoustic field radiated into water by selected ships moving in shallow waters. Underwater acoustic field of ships in motion is associated with acoustic activity of ship mechanisms and equipment under work. Vibration energy radiated by the mechanisms and devices is transmitted by ship structural elements to surrounding water where it is propagated in the form of acoustic waves of a wide frequency band. In this paper are presented results of the research on propagation of energy of acoustic waves in the near fiel, obtained from acoustic pressure measurements by means of two sensors located close to each other.
\end{abstract}

Keywords: energy, propagation, hydroacoustics

\section{INTRODUCTION}

Research on spectral structures of underwater noise generated to water by vessels of different classes have been used for many years in the detection, location and identification systems, and also in the homing guidance and initiation units of sea weapons systems.

Underwater sound field of the vessels is connected with the activity of acoustic wave sources installed on ships, i.e. ship mechanisms and equipment (main engines, generators, gears, pumps, shaft lines, pipes, ducts, etc.) and hydrodynamic sources such as screw propeller and water flow around the hull.

Theoretical estimation of the level of acoustic energy near the wave source and attempts to present the vertical and horizontal distribution of energy in the plane of trajectory are difficult and currently not very effective. This follows from the fact that the theoretical model of extended source, which is a superposition of several different types of sources of acoustic waves, namely those due to water flow (propeller flow, flow around the hull), ship hull vibration and cavitation, makes that their full description is extremely complicated and difficult to apply in practice. A great difficulty is the necessity to take into account the influence of surface limiting water environment (free surface and bottom of sea). The next difficulty is the fact that the waves generated by a ship to water near the sources are non-stationary and nonlinear. It seems that many unknown variable parameters which shape acoustics of the near field of ships make application of adequate numerical models to solve this problem, impossible. For this reason, in practice, the measurements are performed in natural conditions at various depths of ship operation and various set of points of their propulsion systems, and then results of the measurements are recorded and archived in digital form in specialty systems.

To-be-archived sound pressure measurements should be recorded in the far field zone $[1,2]$ i.e. where the following condition is satisfied:

$$
\mathrm{d}^{2} \gg \mathrm{r} \lambda / 2 \pi \text { or } \Delta \mathrm{r} \ll \lambda
$$

where:

$r \quad$ - the distance between source and receiver,

$\Delta \mathrm{r}$ - distance between sensors,

d - maximum linear dimension of the active part of transmitter,

$\lambda \quad$ - acoustic wave length.

For the assumed depth of the coastal water region, amounting from 10 to $70 \mathrm{~m}$ at which underwater noise measurements are made, the condition of the far field would be satisfied for the frequency $\mathrm{f} 31000[\mathrm{~Hz}]$ in the trial area situated at the depth of $10 \mathrm{~m}$. This limitation is also dependent on radiating surface dimension and sound propagation velocity in water.

The sound pressure measurement performed on the measurement depths, does not allow to precisely characterize acoustic field distribution of vessel in motion. Characteristic components of the spectrum generated by the main and auxiliary mechanisms, propeller, shaft line of ships of different classes are contained in the frequency band up to about 150 [Hz]. Sample distributions of hydroacoustic fields of selected vessels are shown in Fig. 1. 

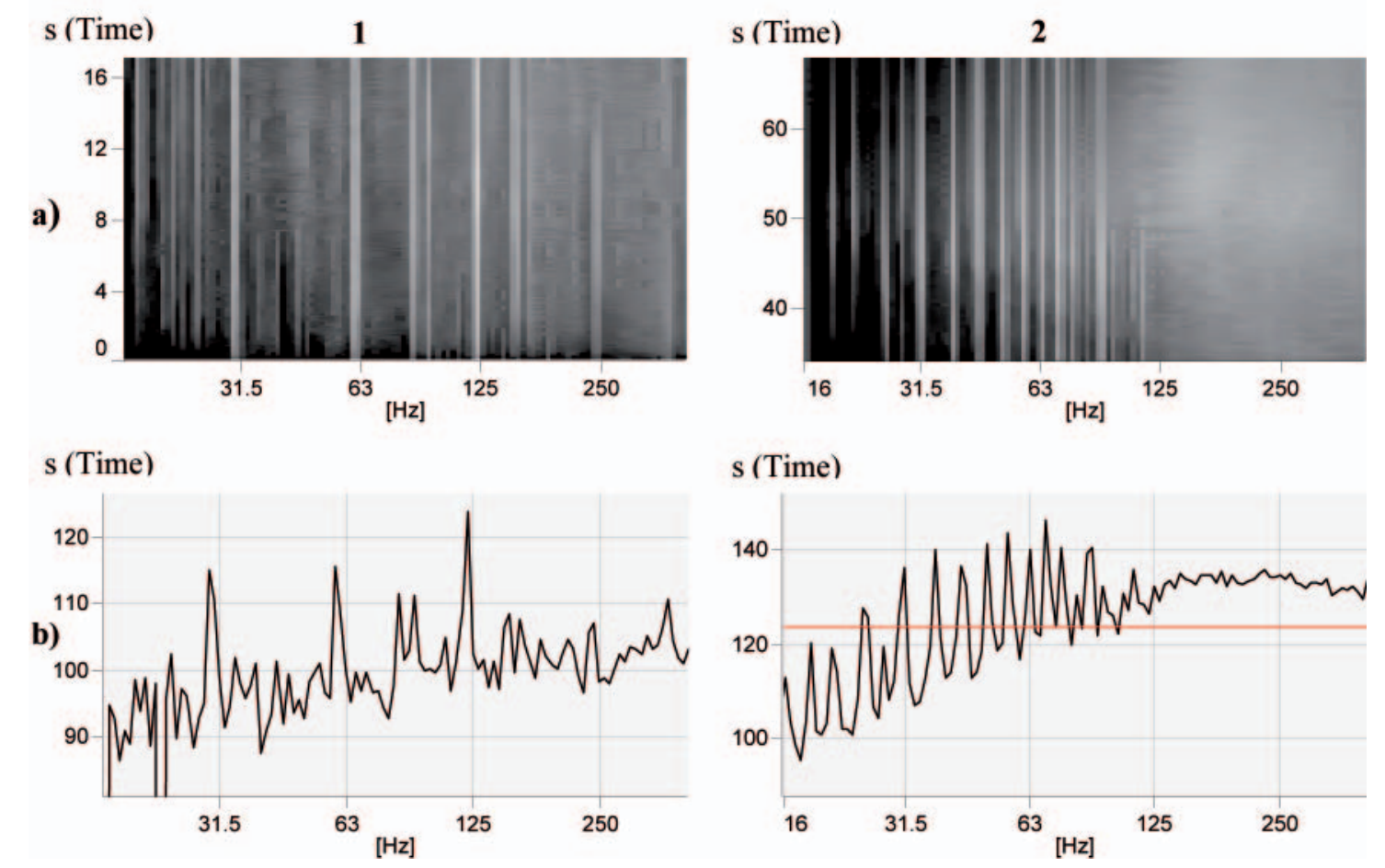

Fig. 1. Example acoustic spectrograms and power spectra of vessels, where:

1 - ship with turbine propulsion system, 2 - ship with conventional propulsion system,

$\boldsymbol{a}$ - the spectrograms made at the frequency band up to $500[\mathrm{~Hz}]$ with resolution of $1 / 24$ octave,

$\boldsymbol{b}$ - the underwater noise spectrum made in the place where the most noisy part of the ship was situated directly above the acoustic sensor

In the presented figures it is clearly visible that the characteristic spectral components, reflecting both the frequency and level of work of the main propulsion systems and auxiliary mechanisms, are located in the frequency band up to about $100[\mathrm{~Hz}]$.

When taking into account the short characteristics of the acoustic field distribution of the above mentioned ships of different classes, it seems evident that that measurement ranges in the frequency domain should cover the whole range of length of acoustic waves propagating from the ships to surrounding water.

Sound intensity measurement of underwater noise enables to carry out more accurate research in this water region. Such measurement based on a suitable spacing of acoustic sensors and precise phase matching of hydrophones and measuring setups, will make it possible to process of recorded data in the frequency band of interest.

In order to determine spatial distribution of acoustic energy it is necessary to know vibration velocity distribution of acoustic wave sources. In the case of vessels to determine precisely vibration velocity distribution on hull shell plating is very difficult because of a complex form of hull surface and limited number of measurement points. In association with the technical and financial difficulties, in the available literature [3, 4] can be found a method for determining the acoustic wave velocity which makes it possible to determine a substitute vibration velocity distribution. Such distribution is determined experimentally by measuring the acoustic pressure and velocity. Measurement of acoustic pressure in an arbitrary point in space is easy to realize. For the measurement it is sufficient to process data from one sensor only, however the system consisted of at least two sensors is necessary to measure the acoustic velocity. The approximate component of acoustic velocity vector, directed along the vector $\vec{r}$ determined from acoustic pressure measurements with the use of two sensors placed close to each other, can be determined from the following relation:

$$
\mathrm{v}_{\mathrm{r}}=-\frac{1}{\rho \Delta \mathrm{r}} \int\left(\mathrm{p}_{\mathrm{B}}-\mathrm{p}_{\mathrm{A}}\right) \mathrm{dt}
$$

where:

$\mathrm{P}_{\mathrm{B}}-\mathrm{P}_{\mathrm{A}}$ - pressure difference at the points $\mathrm{A}$ and $\mathrm{B}$, $\rho$ - density of medium.

The approximation can be applied to the far field in which the relation (1) is satisfied. During the acoustic velocity measurements the measured values of sound pressure are often converted from analogue to digital form.

where:

$$
\mathrm{v}_{\mathrm{r}}(\mathrm{n})=\mathrm{v}_{0}-\frac{\Delta \mathrm{t}}{\rho \Delta \mathrm{r}}\left[\mathrm{p}_{\mathrm{B}}(\mathrm{i})-\mathrm{p}_{\mathrm{A}}(\mathrm{i})\right]
$$

$\mathrm{v}_{0}$ - constant component of velocity which can be determined after calculation of velocity values for the entire wave period.

The resulting acoustic velocity is used to determine the acoustic wave intensity which, for stationary signals, can be described by the dependence:

$$
I(r)=\overline{p(r, t) v(r, t)}
$$

Taking into account the dependence (3) we obtain:

$$
I=\frac{1}{2 \rho \Delta r} \overline{\left(p_{A}+p_{B}\right) \int\left(p_{B}-p_{A}\right) d t}
$$

And, after an appropriate transformation the digital dependence (5) takes the form:

$$
\mathrm{I}=\frac{1}{2 \pi \mathrm{k} \rho \Delta \mathrm{r}} \cdot \operatorname{Im}\left[\mathrm{G}_{\mathrm{xy}}(\mathrm{k})\right]
$$

where:

$0<\mathrm{k}<\mathrm{N}$

$\operatorname{Im}\left[\mathrm{G}_{\mathrm{xy}}(\mathrm{k})\right]$ - complex part of cross spectrum. 


\section{LIMITATIONS OF THE PRESENTED METHOD}

The method used to measure sound intensity with the use of two sensors located close to each other, has some limitations. The basic error of this method is connected with inaccuracy of measuring the derivative of hydroacoustic pressure. The error is observed in the higher frequency ranges. For a flat harmonic wave, the estimated value of related to the exact value of $\hat{I}$ the sound intensity I, can be determined from the dependence (7):

where:

$$
\frac{\hat{\mathrm{I}}}{\mathrm{I}}=\frac{\sin (\mathrm{k} \Delta \mathrm{r})}{\mathrm{k} \Delta \mathrm{r}}
$$

$\mathrm{k}$ - wave number.

In the logarithmic form the dependence is as follows:

$$
\mathrm{L}=10 \lg \left(\frac{\sin (\mathrm{k} \Delta \mathrm{r})}{\mathrm{k} \Delta \mathrm{r}}\right)
$$

For the spherical wave, the estimated value of Î related to the exact value of the sound intensity I, can be determined from the dependence (9):

$$
\frac{\hat{\mathrm{I}}}{\mathrm{I}}=\frac{\sin (\mathrm{k} \Delta \mathrm{r})}{\mathrm{k} \Delta \mathrm{r}}\left(1-\frac{1}{4}\left(\frac{\Delta \mathrm{r}}{\mathrm{r}}\right)^{2}\right)^{-1}
$$

An essential error of the method in the low frequency ranges is a deviation resulting from the phase mismatch of measuring setups $[2,3]$. For this reason, we should tend to exactly match the phases of all the measuring setups at which $\varphi \rightarrow 0$. If the phase mismatch occurs between the two setups for flat wave then the estimate of I - value related to the exact sound intensity I, can be determined by using the relation (10):

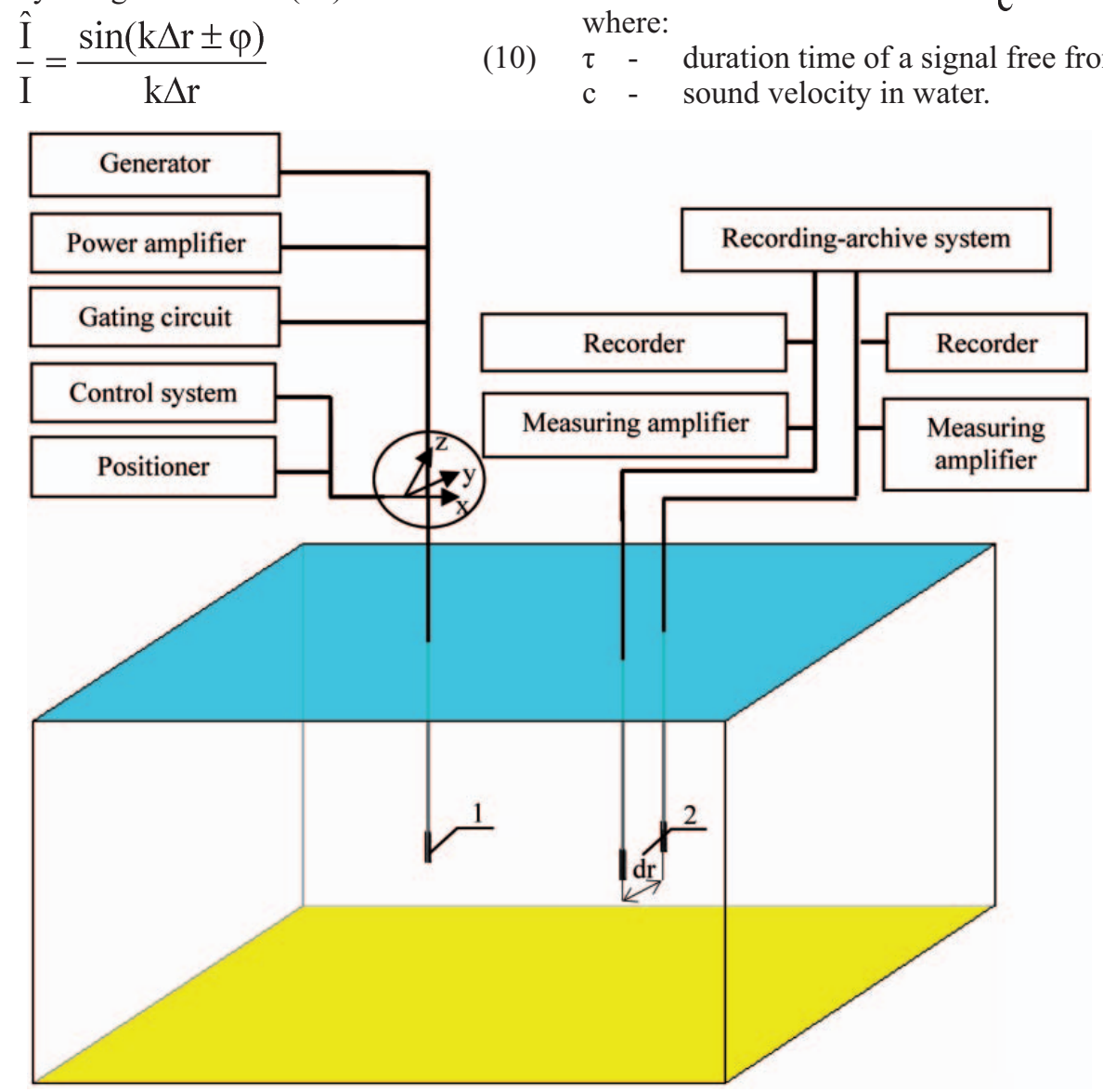

Fig. 2. Block diagram of the measuring system including the tank. Notation: 1 - sending hydrophone, 2 - receiving hydrophones

\section{CALIBRATION OF MEASURING SETUPS}

In order to obtain authentic results of measurements it is necessary to perform accurate calibration of measuring setups to determine the exact phase difference of measuring setups. To determine the differences the method of submission of mutually perpendicular harmonic signals has been used. The curve obtained as a result of the composing of signals is dependent on frequency and phase of the signals as well as values of their amplitudes. Results of the composing of signals were published first by Lissajous, a French scientist, at the end of $19^{\text {th }}$ century.

The laboratory calibration tests of the measuring setup of the probe for underwater, measuring the sound intensity have been performed in a measuring tank. The block diagram of the measuring system including the tank, is shown in Fig. 2.

In order to eliminate the waves reflected from the tank walls and water surface the system has been applied for calibrating the sensor by means of the impulse method [2], which makes it possible to eliminate unfavorable reflected waves by suitable selection of duration time of pulses of harmonic waves generated in appropriate time intervals. The duration times of sending pulses resulted from the basin's geometry and were determined for the reflections from the tank walls from the dependence:

$$
\tau \leq \frac{1-\mathrm{r}}{\mathrm{c}}, \tau \leq \frac{\sqrt{\mathrm{r}^{2}+\mathrm{b}^{2}}-\mathrm{r}}{\mathrm{c}}
$$

- for reflections from the bottom and surface:

$$
\tau \leq \frac{\sqrt{\mathrm{r}^{2}+\mathrm{h}^{2}}-\mathrm{r}}{\mathrm{c}}
$$

- for the reflections between hydrophones:

$$
\tau \leq \frac{2 \mathrm{r}}{\mathrm{c}}
$$

where:

$\tau$ - duration time of a signal free from reflected signals,

c - sound velocity in water. 
From the far field condition (1.1), by knowing the maximum linear dimension of the transmitter, $\mathrm{d} \leq 0.1 \mathrm{~m}$, and the sound velocity in water, $\mathrm{c}=1480 \mathrm{~m} / \mathrm{s}$, the minimum distance from the receiving hydrophones to the sending one, has been determined at the frequency for which the measurement system has been controlled.

Tab. 1. The length of the near field transmitter for

\begin{tabular}{|c|c|c|c|c|c|c|}
\hline $\mathrm{f}[\mathrm{kHz}]$ & 5 & 6 & 7 & 8 & 9 & 10 \\
\hline $\mathrm{d}^{2} \mathrm{f} / \mathrm{c}[\mathrm{m}]$ & 0.033 & 0.041 & 0.047 & 0.054 & 0.061 & 0.068 \\
\hline
\end{tabular}

The measurements were performed for the distance between receiving and sending hydrophones, $\mathrm{r} \leq 0.4 \mathrm{~m}$, and the pulse duration which could not be longer than $\mathrm{t} \leq 0.4 \mathrm{~s}$, taking into account the dependence (11), (12) and (13).

The tested probe consisted of two 4032 RESON hydrophones spaced at the distance $\ddot{\mathrm{r}} \mathrm{r}=38 \mathrm{~mm}$, and having the sensitivity values:

A - no. $3702080: 170.4 \mathrm{~dB}$ at $250 \mathrm{~Hz} ; 169,1 \mathrm{~dB}$ at $8 \mathrm{kHz}$, $\mathrm{B}$ - no. $3702082: 170.3 \mathrm{~dB}$ at $250 \mathrm{~Hz} ; 169 \mathrm{~dB}$ at $8 \mathrm{kHz}$.

The difference in sensitivity of the sensors in the band of interest, up to $10 \mathrm{kHz}$, is negligible. The significant differences in the indicated levels, reaching from 3 to $10 \mathrm{~dB}$, occurred in the frequency band from 20 to $100 \mathrm{kHz}$. The $8100 \mathrm{Brüel} \& \mathrm{Kjar}$ hydrophone which generated acoustic wave in the frequency ranges given in Tab. 1, served as a source of harmonic waves. The sinusoidal signal from the generator was transmitted to the 4440 Brüel \& Kjar gate which controlled the length and pulse repetition frequency. The signal from the gate was properly amplified by 2713 Brüel \& Kjar power amplifier and then transmitted in the form of short pulses of harmonic wave, to the surrounding water by the sending hydrophone. The acoustic wave produced by the hydrophone was received by two receiving hydrophones placed at equal distances from the sending sensor. Signals received by them were amplified by 2636 Brüel \& Kjar amplifiers, and then recorded and processed in a analyzer which made it possible to determine mismatch of the tested phases of the system. The extensive results of the performed calibration of the probe are contained in the report from realization of this work [2] performed at the Radiolocation and Hydrolocation Department of Polish Naval Academy in Gdynia. The publication presents only representative results of the probe calibration, recorded in the form of Lissajous curves.

From the measurements performed for the probe in question it can be concluded that the phase mismatch of the measuring setups did not exceed $0.2^{\circ}$ for the tested wave length. The level of phase mismatch was enlarged to $0.3^{\circ}$ after taking into account the specific conditions of measurements conducted in the dynamic trial areas. The lower frequency range for different distances between sensors was calculated for this value (acc. Eq. 10).

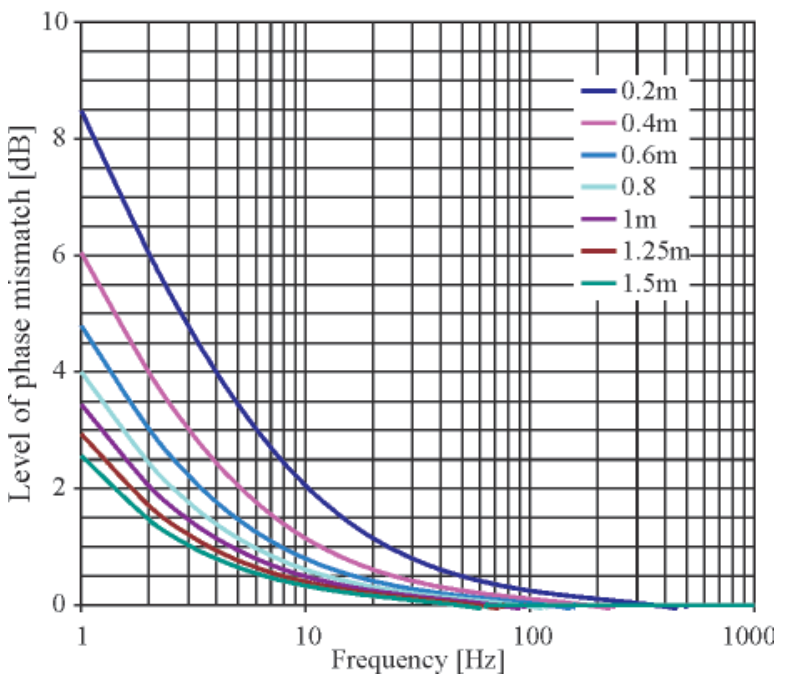

Fig. 4. The values of the phase mismatch level of the lower frequency range for the distance between sensors $\Delta r=0.2,0.4,0.6,0.8,1,1.25,1.5 \mathrm{~m}$, respectively

The upper frequency range for the same distance was determined in the same way by taking into account the dependence (7). On the basis of those frequency ranges the frequency range at which the error does not exceed $1[\mathrm{~dB}]$, was determined.

On the basis of the performed research it can be concluded that, for the phase mismatch level of $0.3^{\circ}$, measurements in dynamic trial areas can be conducted in the frequency range from $10[\mathrm{~Hz}] \pm 2[\mathrm{~dB}]$ to $1325 \pm 1[\mathrm{~dB}]$ and at the spacing between hydrophones equal to 0.2 [m]. The described sound intensity measuring method makes performing the tests within the specified frequency band in the coastal zone, possible.

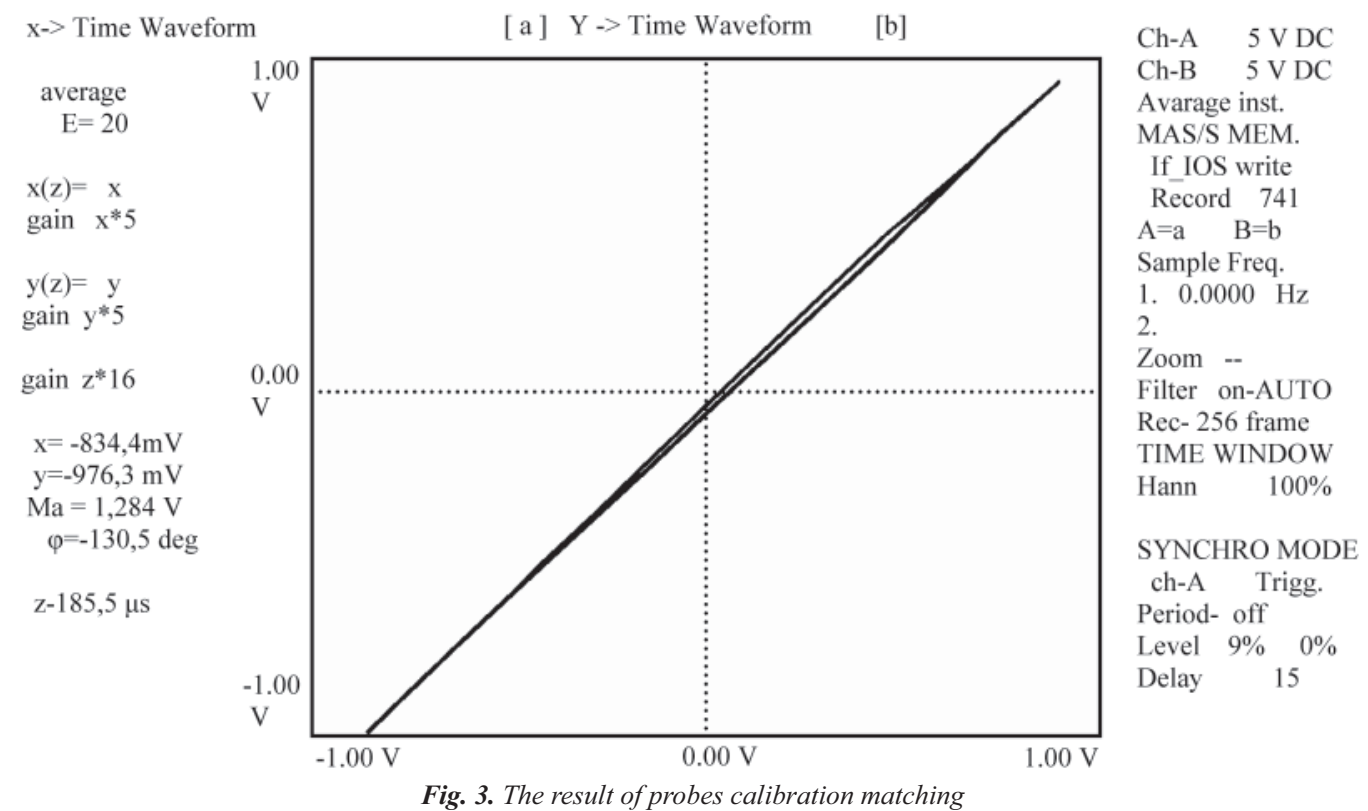




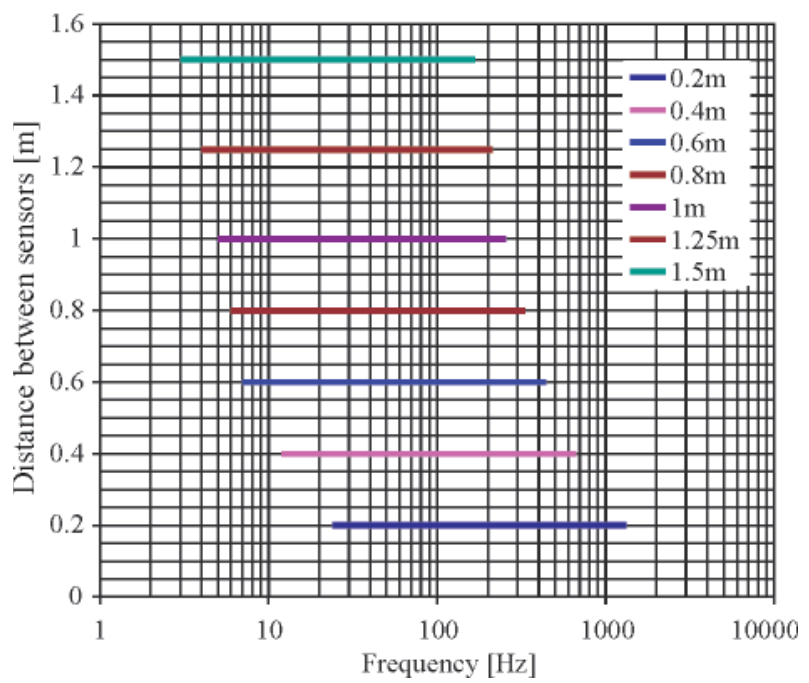

Fig. 5. The frequency ranges of the sound intensity measurement at which the error does not exceed $1[\mathrm{~dB}]$

\section{DYNAMIC MEASUREMENTS}

The acoustic noise measurements of submarines are repeated periodically during operation of each ship. During the measurements ships pass at least twice through the trial area with the set work parameters of the propulsion system. The determined ship parameters are reached at the distance of $300 \mathrm{~m}$ at least before the trial area and maintained over the distance of $600 \mathrm{~m}$ at least ( $300 \mathrm{~m}$ behind the buoys). Sound pressure measurements are made at a distance afore and astern the ship to make it possible to characterize underwater disturbances of the ship. The passage of ship through the trial area is very often presented in the form of sound pressure in function of time and frequency. The spectrogram of the performed recording is presented in Fig. 6.

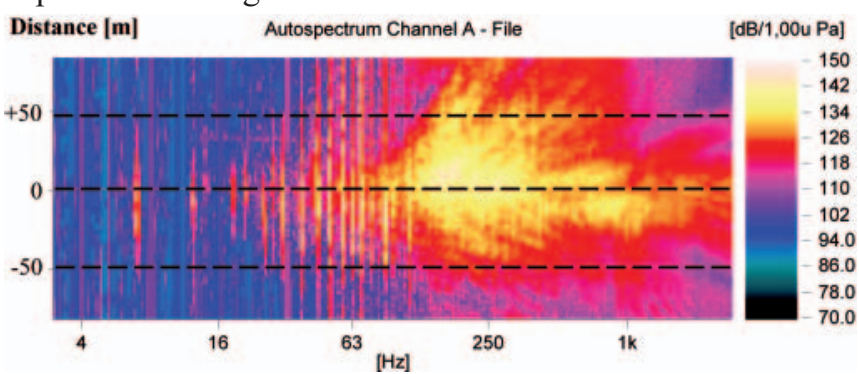

Fig. 6. The acoustic field spectrogram of the ship moving with forward speed of $4 \mathrm{kn}$

The spectrogram consists of 299 spectra recorded every 312 [ms] with the resolution of 0.04167 octave in the frequency range from $3[\mathrm{~Hz}]$ to $2.818[\mathrm{kHz}]$. Broken lines mark the distance of the ship from the acoustic sensor.

In the spectrogram two areas are clearly visible. The first area contains frequencies to about $100[\mathrm{~Hz}]$. In this area the characteristic spectrum components resulting from working ship mechanisms, can be observed. The second area of the frequency range from $100[\mathrm{~Hz}]$ to $2.8[\mathrm{kHz}]$ contains a continuous spectrum. The spectrum is connected with work of cavitating propeller, turbulent flow in pipelines, flow around the hull, airflow in ventilators, etc. Such analysis makes it possible to select, out of the spectrogram, a spectrum in an arbitrary area covered by the measurements.

Fig. 7 presents the ship's spectra taken from the places pointed in the spectrogram. The first of them was recorded when the most noisy part of the ship was situated about $50[\mathrm{~m}]$ before the acoustic sensor. The second - when the disturbance source was just above the sensor, and the third one - corresponds with the distance of $50[\mathrm{~m}]$ behind the sensor.

The two previously discussed areas are also visible in the spectrum in question. From them it can be also observed that before the trial area the ship generates mainly waves connected with work of mechanisms and ship equipment, and behind it the waves connected with work of the propeller are dominant. To more clearly present the figures, the signal recorded when the ship passed just above the acoustic sensor, was suppressed by $30[\mathrm{~dB}]$, and that corresponding with the distance of $50[\mathrm{~m}]$ behind the trial area - by $60[\mathrm{~dB}]$.

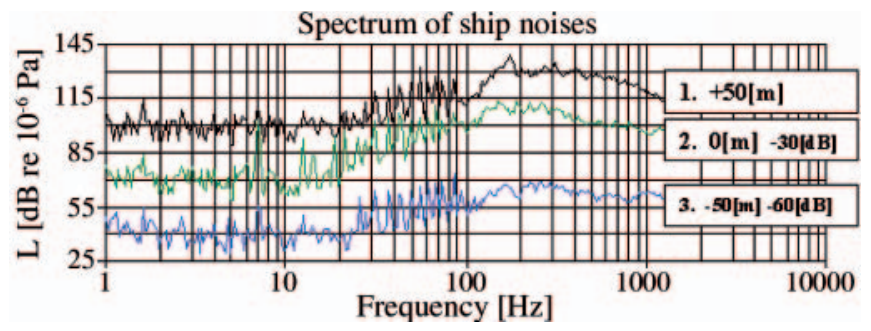

Fig. 7. The spectra obtained at some distance before and behind the trial area, as well as during passing just above the acoustic sensor.

Notation: 1 - the spectrum of the ship taken 50[m] behind the trial area, 2 - the spectrum recorded when the most noisy part of the ship passes above the acoustic sensor, 3 - the spectrum of the ship taken $50[\mathrm{~m}]$ before the trial area

The characteristic components visible in the first area can be unambiguously assigned to working mechanisms and equipment of the ship. Examination of ship spectrum is one of the methods for identification of ship underwater noise. In order to carry out identification of the components such tests are usually performed in two stages. The first contains measurements carried out on anchored ship. The measurements consist in the measuring of vibration of main mechanisms and auxiliary equipment of the ship, accompanied with the simultaneous measuring of sound pressure in water depth. In the second stage the ship crosses dynamic trail areas, under various operational settings of its propulsion system. During the measurements both underwater noise and vibration of selected mechanisms and equipment, are recorded. On the basis of the measurements it is possible to characterize the components visible in the first presented field. To identify the components, an analysis with using constant band width filters for the tested frequency band, is often performed. A representative identification analysis of the spectrum of the ship in motion is shown in Fig. 8.

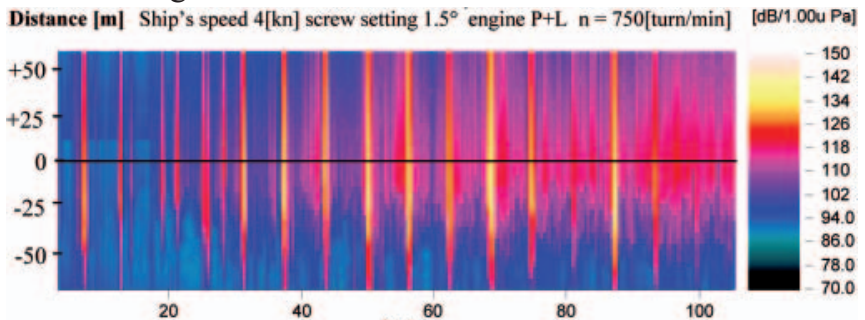

Fig. 8. The acoustic field spectrogram of the ship with forward speed of $4 \mathrm{kn}$, recorded in the frequency band up to $100[\mathrm{~Hz}]$

The spectrogram consists of 74 spectra recorded every $1.333[\mathrm{~s}]$ with the resolution of $0.25[\mathrm{~Hz}]$ in the frequency band up to $100[\mathrm{~Hz}]$. From the figure was selected the spectrum when the ship's power plant was situated just above the acoustic sensor (the place distinguished with black line at the spectrogram).

The figure clearly shows discrete spikes coming from working main engines, shaft lines and propeller, and a single spike marked "I" in red color, coming from an electric generating 


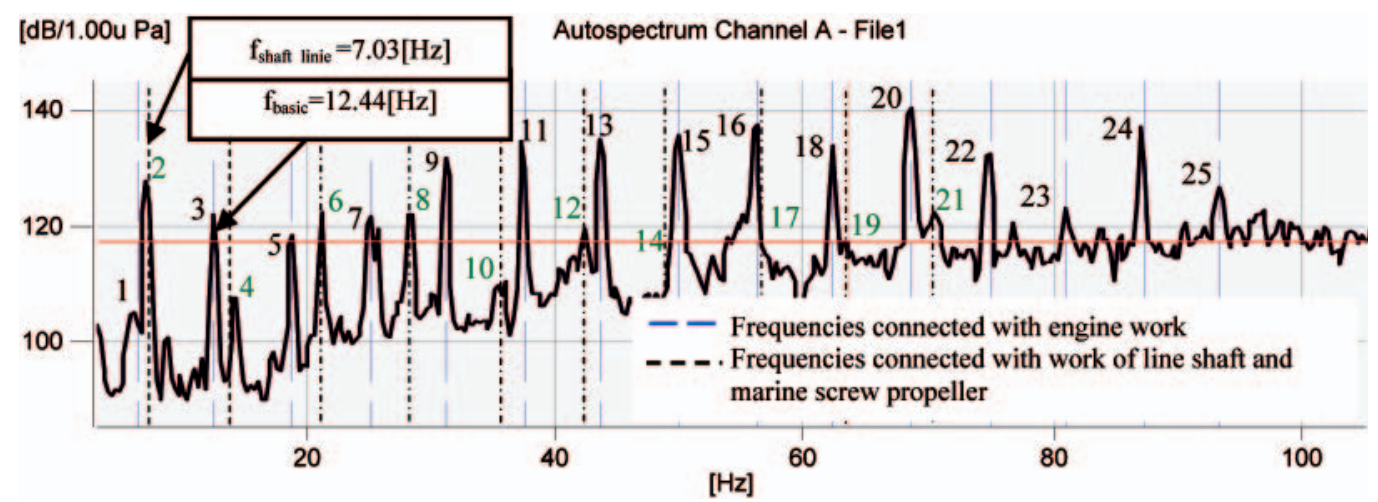

Fig. 9. The ship acoustic power spectrum recorded at the distance marked "0" in Fig. 8

set under operation. Each discrete spike was distinguished by a successive number, namely green numbers indicate spikes coming from propeller and shaft lines, and black numbers show spikes coming from working main engines. Additionally, each discrete spike was distinguished by broken line, namely blue lines stand for the frequencies connected with work of main engines, and black lines - the frequencies connected with rotation of shaft line and propeller. The identification results obtained by using the method in question have been published many times $[8,12,16]$. This paper presents only a single analysis performed for a given working regime of ship propulsion system. The authors' archive contains results of identification of ships of different classes, made for various working regimes of their propulsion systems.

Among the relationships which are most commonly elaborated on the basis of such measurements, can be numbered the above presented characteristics of the sound pressure level in function of frequency, obtained for an arbitrary phase of ship's passing through the trial area, as well as the following: a) the sound pressure level in function of distance,

b) the sound pressure level in function of ship forward speed and water depth,

c) the relation between underwater noise and vibration of ship mechanisms.

The sample characteristic relation of sound pressure level in function of distance between ship and sensor, and of ship forward speed, is shown in Fig. 10 and 11. The curves were determined on the basis of many repeated measurements performed in the trial area located in the same place, and during the measurements of the ship crossing the trial area under the same work regime of its propulsion system. Results of the measurements were then subjected to relevant statistical

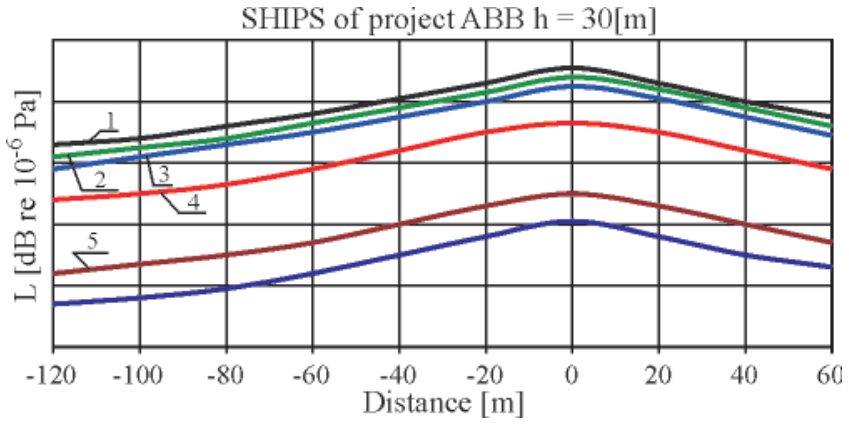

Fig. 10. The characteristic relation of the sound pressure level in function of distance between ship and acoustic sensor. Measurements of the ships were performed at the water depth $h=30[\mathrm{~m}]$. Notation:

1 - the measurements performed at the speed $v=14.5[\mathrm{kn}]$,

2 - the measurements performed at the speed $v=12.5[\mathrm{kn}]$.

3 - the measurements performed at the speed $v=8.5[\mathrm{kn}]$,

4 - the measurements performed at the speed $v=5.5[\mathrm{kn}]$,

5 - the measurements performed at the speed $v=2.5[\mathrm{kn}]$ processing and approximating procedure. The approximation by means of polynomial of the second or third order is most commonly used to approximate the relation of pressure levels in function of ship distance, water depth and ship forward speed.

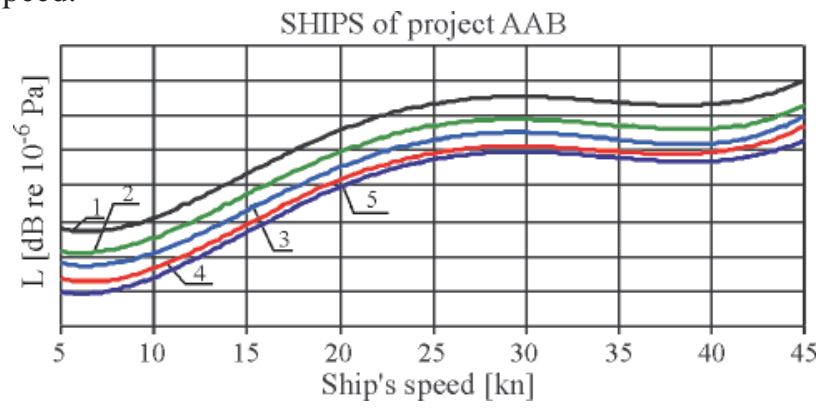

Fig. 11. The relation of the sound pressure level as a function of ship's forward speed. Notation:

1 - the measurements performed at the water depth $h=10[\mathrm{~m}]$.

2 - the measurements performed at the water depth $h=20[\mathrm{~m}]$,

3 - the measurements performed at the water depth $h=30[\mathrm{~m}]$,

4 - the measurements performed at the water depth $h=40[\mathrm{~m}]$,

5 - the measurements performed at the water depth $h=50[\mathrm{~m}]$

In the paper possible ways of extending the measuring range due to a change in measurement methods, are mainly presented. To make performing the sound intensity measurements possible, the trial area was additionally equipped with a pair of sensors tested in laboratory, and positioned along the assigned path of ship through the area. In order to verify correctness of indications of the probe, the measurement results of noise propagating from the sensors of the probe were compared to each other, and the hydroacoustic pressure levels in the selected frequency bands were also compared.

The equal values of the levels obtained from the sensor probe, in the considered frequency bands, and given in the point $(\mathrm{L}=138[\mathrm{~dB}], \mathrm{f}=930,6[\mathrm{~Hz}], \mathrm{t}=23,10[\mathrm{~s}])$ distinguished by the cursor at the spectrograms, and the character of underwater noise distribution confirmed the possibility of conducting mutual analyses by the tested probe, which should enrich in consequence knowledge on underwater noise.

One of the fundamental features which differed the sound intensity measurement from the sound pressure one is the possibility of determining the phase differences between active and passive part of the sound field [3], which allows to determine direction of propagation of acoustic waves in water.

In view of the limitations imposed on the application of the measurement method in question, revealed by the equations (10) and (12), the frequency band for processing the measurement results was reduced from $6.9[\mathrm{~Hz}]$ to $1.334[\mathrm{kHz}]$. The accuracy of value of the level for the frequency of $6.9[\mathrm{~Hz}]$ should not exceed $3[\mathrm{~dB}]$, and for the upper frequency: $1[\mathrm{~dB}]$. 


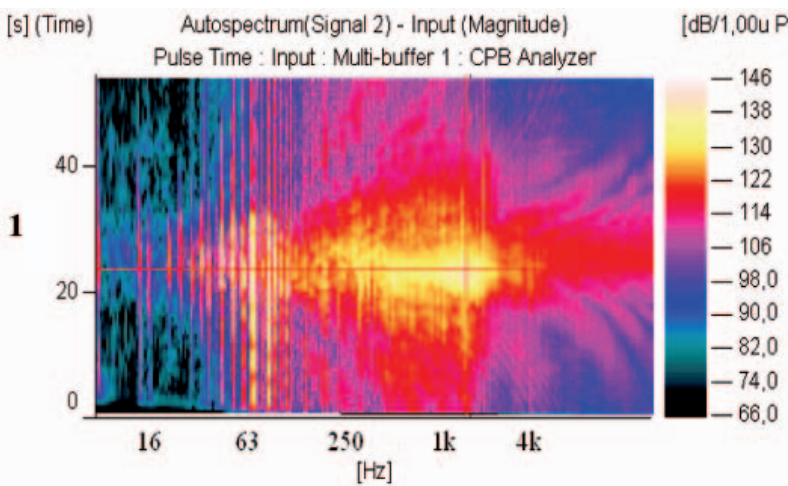

dB/1,00u Pa] [dB/1,00E-6 Pa] Autospectrum(Signal 3) - Input - slice1
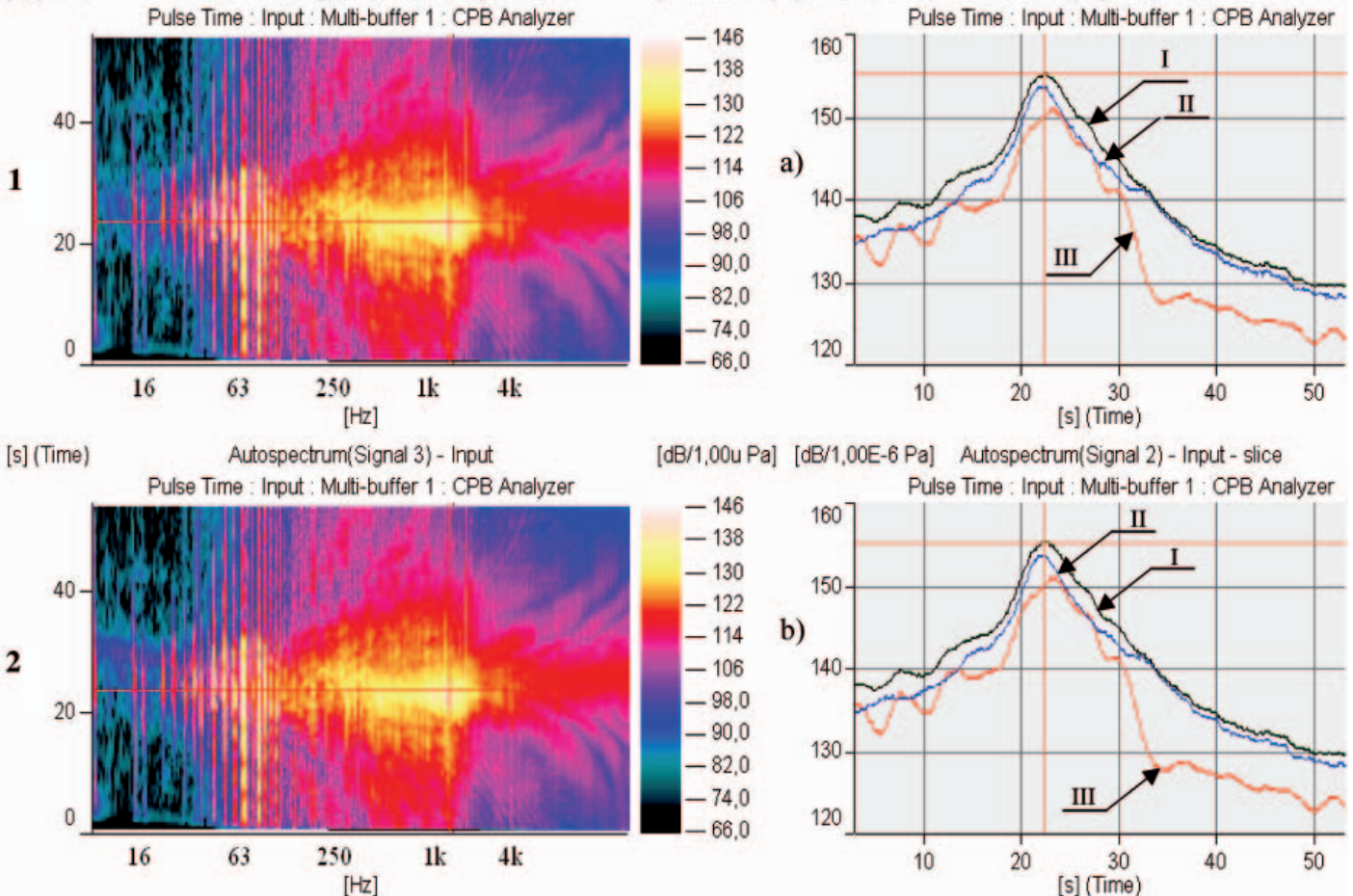

[B/1,00u Pa] [dB/1,00E-6 Pa] Autospectrum(Signal 2) - Input - slice

Fig. 12. The measurement results of hydroacoustic pressure recorded by using the probe

for measuring the sound intensity of the ship moving with forward speed of $6.6 \mathrm{kn}$.

Notation: 1, 2 - the spectrograms of the ship acoustic field obtained from the sensor probe at the frequency band from 6.9 [Hz] to 11.22 [kHz],

$\boldsymbol{a}, \boldsymbol{b}$ - the relation of the pressure levels in function of duration time of ship passage through the trial area, obtained for the following frequency bands: $\boldsymbol{I}$ - the pressure value $L=155[\mathrm{~dB}]$ in the band from $6,9[\mathrm{~Hz}]$ to $11.22[\mathrm{kHz}$,

II - the pressure value $L=154[\mathrm{~dB}]$ in the band from $100[\mathrm{~Hz}]$ to $11.22[\mathrm{kHz}]$

III - the pressure value $L=151[\mathrm{~dB}]$ in the band from $6.9[\mathrm{~Hz}]$ to $100[\mathrm{~Hz}]$.

From the pressure measurements presented in the spectrogram of Fig. 12 the sound intensity was determined in accordance with the equation (1.6).

[s] (Time) Calc. Intensity Spectrum() (Magnitude)

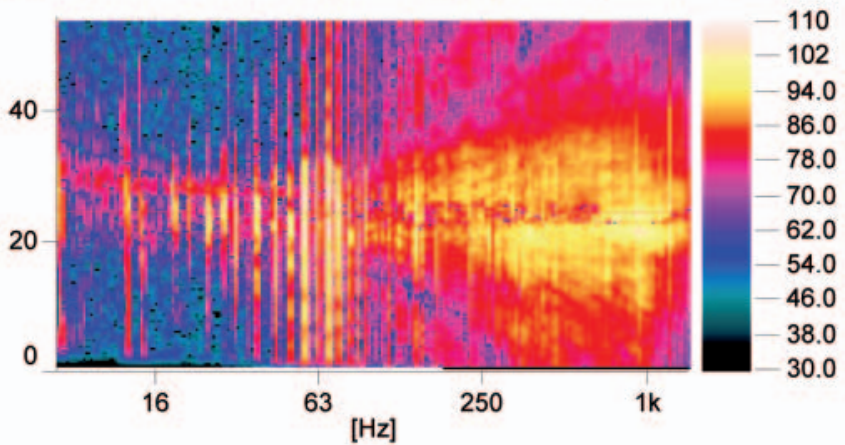

Cursor Values

$\mathrm{Y}=74.6 \mathrm{~dB} / 1.00 \mathrm{p} \mathrm{W} / \mathrm{m}^{2} \quad 2006-04-20$ 11:34:33.073 Sum $=112 \mathrm{~dB}-11.00 \mathrm{p} \mathrm{W} / \mathrm{m}^{2}$ $\mathrm{X}=53.86 \mathrm{~Hz} \quad$ Overaging time: $1 \mathrm{~s}$

$\mathrm{Z}=24.10 \mathrm{~s}$

Fig. 13. The spectrogram of underwater noise intensity obtained in the frequency band from $6.9[\mathrm{~Hz}]$ to $1.334[\mathrm{kHz}]$

When testing the sound intensity amplitude of passage of the ship with the course of $0^{\circ}$ relative to the location of the axis of the sensor probe, it should be demonstrated that on the basis of measurements in real conditions it is possible to precisely locate the place of passage of the ship above the set of acoustic sensors. To determine the location is possible because in laboratory conditions the value of sound pressure level falls to " 0 " for perpendicular position of the sound source relative to the probe. The phenomenon is described in many publications $[4,5,6]$, and confirmed in laboratory tests carried out on the probe. A local depreciation of sound intensity revealed on the spectrogram are visible for about 24 [s] duration time of passage of the ship above the probe. For different wave lengths we can observe of course different instants in which such local reduction of the sound intensity level would occur. The sound pressure level spectrum in function of time for the previously selected frequency ranges was produced to accurately reveal the local minimum values. In the spectra shown in Fig. 14, are clearly visible the local minimum values of the sound intensity level, by which perpendicular direction of hydroacoustic wave propagation relative to the probe in selected areas, is determined.

\section{[dB/1,00E-12 W/m²] Calc. Intensity Spectrum() (Magnitude)}

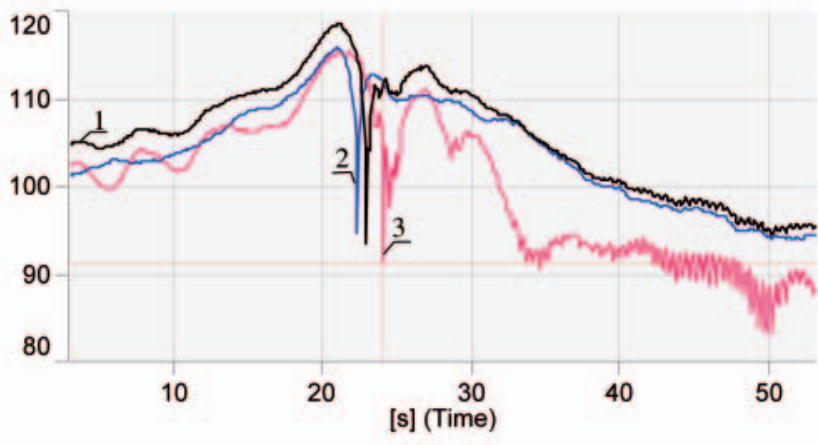

Cursor Values

Status

Slice Definition

$Y=91.3 \mathrm{~dB} / 1.00 \mathrm{E}-12 \mathrm{~W} / \mathrm{m}^{2} \quad$ 2006-04-20 11:34:33.073 Freq. Band Slice 1 (Sum) $X=53.44 \mathrm{~Hz} \quad$ Averaging time: $1 \mathrm{~s} \quad$ Start $=6.879 \mathrm{~Hz}$ $Z=24.10 \mathrm{~s}$

Fig. 14. The spectra of sound intensity level as a function of duration time of passage of the ship above the probe, obtained for the selected frequency bands: 1 - the minimum value of sound intensity level $L=93.4[\mathrm{~dB}]$, for the time $t=22.90[\mathrm{~s}]$, in the frequency band from $6.9[\mathrm{~Hz}]$ to $1.334[\mathrm{kHz}]$;

2 - the minimum value of sound intensity level $L=94,7[\mathrm{~dB}]$, for the time $t=22.30[\mathrm{~s}]$, in the frequency band from $100[\mathrm{~Hz}]$ to $1.334[\mathrm{kHz}]$; 3 - the minimum value of sound intensity level $L=91.3[\mathrm{~dB}]$, for the time $t=24.10[\mathrm{~s}]$, in the frequency band from $6.9[\mathrm{~Hz}]$ to $100[\mathrm{~Hz}]$ 
The places of occurrence of local minimum values of sound intensity level determine a change of direction of energy flow to the probe. The change of direction can be showed by using the analysis of real part of complex spectra of sound intensity level. Results of the performed analysis is shown in Fig.15.

\section{[dB/1.00E-12 W/m²] Calc. Intensity Spectrum()}

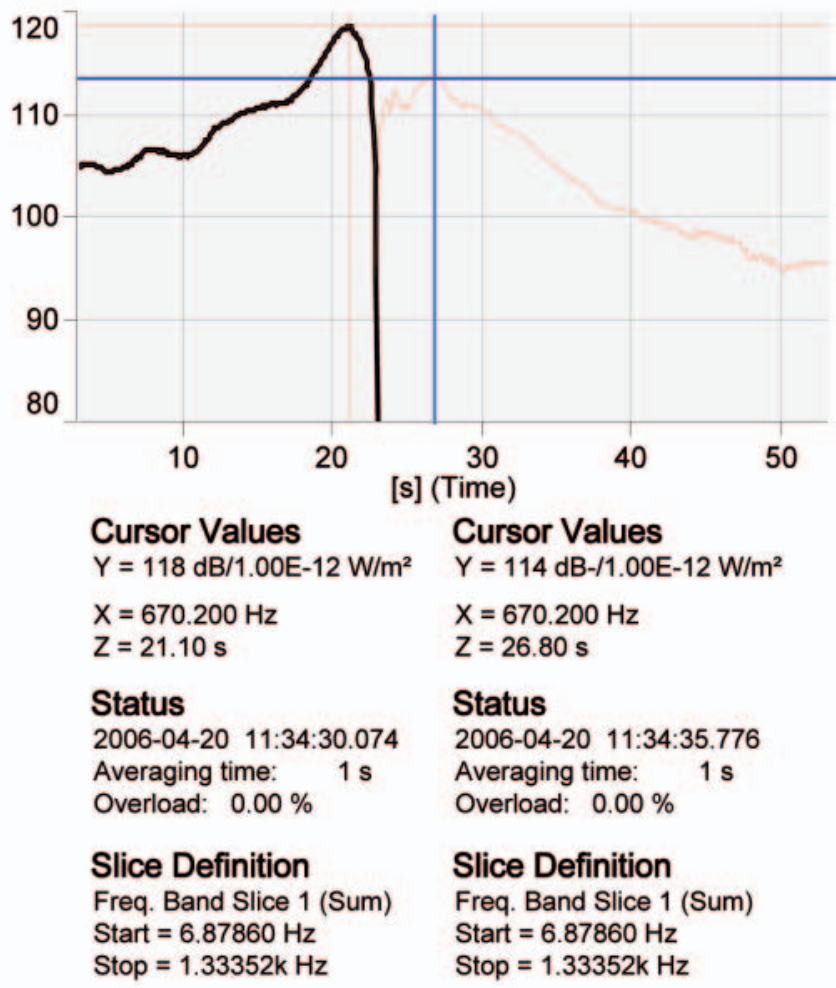

Fig. 15. The spectrum of real part of complex spectra of sound intensity level, performed in the frequency range from $6.9[\mathrm{~Hz}]$ to $1.33[\mathrm{kHz}]$

On the presented diagram of the analysis of absolute value of sound intensity level in function of duration time of passage of the ship above the probe the discussed change in energy flow direction is clearly visible. Positive value of sound pressure can be observed up to 22.90 [s] of duration time of passage of the ship through the trial area, represented by the black curve in Fig. 15. The black curve shows negative value of sound intensity. And, the maximum value of sound intensity $\mathrm{L}=+118[\mathrm{~dB}]$ re $10^{-12}[\mathrm{~W} / \mathrm{m} 2]$ ( distinguished by cursor ) is observed at $\mathrm{t}=21.10[\mathrm{~s}]$, and the minimum value $\mathrm{L}=-114$ - at $\mathrm{t}=26.80$ [s]. The spectra obtained from the spectrogram presented in Fig. 13, which were taken for an arbitrary approaching time of ship to the probe and during its departure from the trial area, can also show the reversal of sign of sound intensity level.

From the spectra presented in Fig. 16 and 17, the summary sound intensity levels equal to $L=+113[\mathrm{~dB}$ ] for the upper spectrum and $\mathrm{L}=-103[\mathrm{~dB}]$ for the lower spectrum, respectively, can be read. The reversal of sign of sound intensity level constitutes a confirmation that reversal of direction of energy flow to the sensor probe takes also place.

Reversal of direction of energy flow, determined from the measurment of difference of pressure values obtained from two hydroacoustic sensors makes it possible to determine direction of the source relative to location of the probe, within the sector from $-90^{\circ}$ to $+90^{\circ}$. Determination of the source direction by means of this method is rather inaccurate.

Such measurement informs only whether the acoustic noise source is situated before the perpendicular plane located in half-distance between sensors, or behind it.
A more accurate bearing of the probe equipped with a pair of sensors can be obtained by testing both the sign of sound intensity and phase of the signal between the active and passive part of the sound field. For this purpose the tested noise was so processed as to obtain the spectrogram of amplitude of underwater noise phases, from which it was possible to determine the phase $\left[^{\circ}\right]$ within the considered frequency ranges.

$\left[\mathrm{dB} / 1.00 \mathrm{p} \mathrm{W} / \mathrm{m}^{2}\right] \quad$ Calc. Intensity Spectrum()

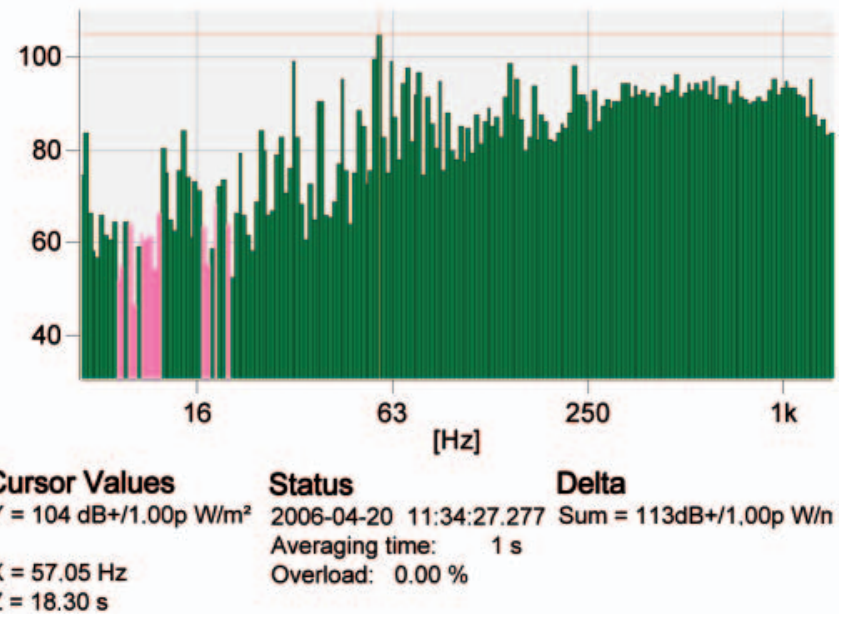

Fig. 16. Spectrum of sound intensity in function of frequency, obtained during approaching the ship to the probe.

$\left[\mathrm{dB} / 1,00 \mathrm{p} \mathrm{W} / \mathrm{m}^{2}\right] \quad$ Calc. Intensity Spectrum()

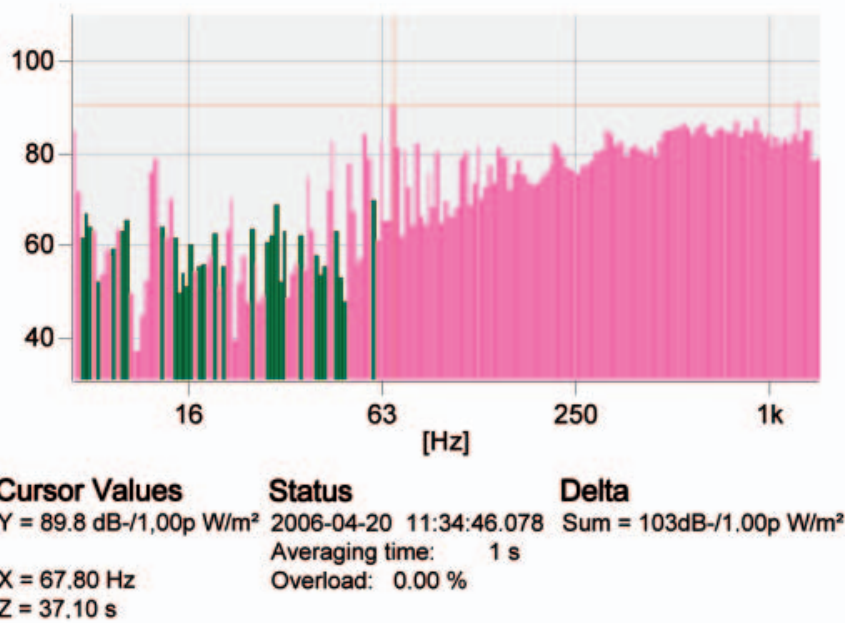

Fig. 17. The spectrum of sound intensity in function of frequency, obtained during departing the ship from above the probe

The spectrogram of phase amplitude of underwater noise (phase-assigned auto-spectrum) was calculated from the dependence:

$$
\varphi_{\mathrm{xy}}=\frac{\varphi_{\mathrm{xy}}}{\left|\varphi_{\mathrm{xy}}\right|}
$$

where:

$\mathrm{x}=$ the active component of sound field,

$\mathrm{y}=$ the reactive component of sound field.

The spectra of underwater noise phases were determined in the selected frequency bands, Fig. 18.III. They are only useful in determining the sign of phase during performance of the measurement. The spectra were determined from the underwater noise phases, Fig. 18.II, for the whole duration time of the measurement. Examining the figures we can observe that 

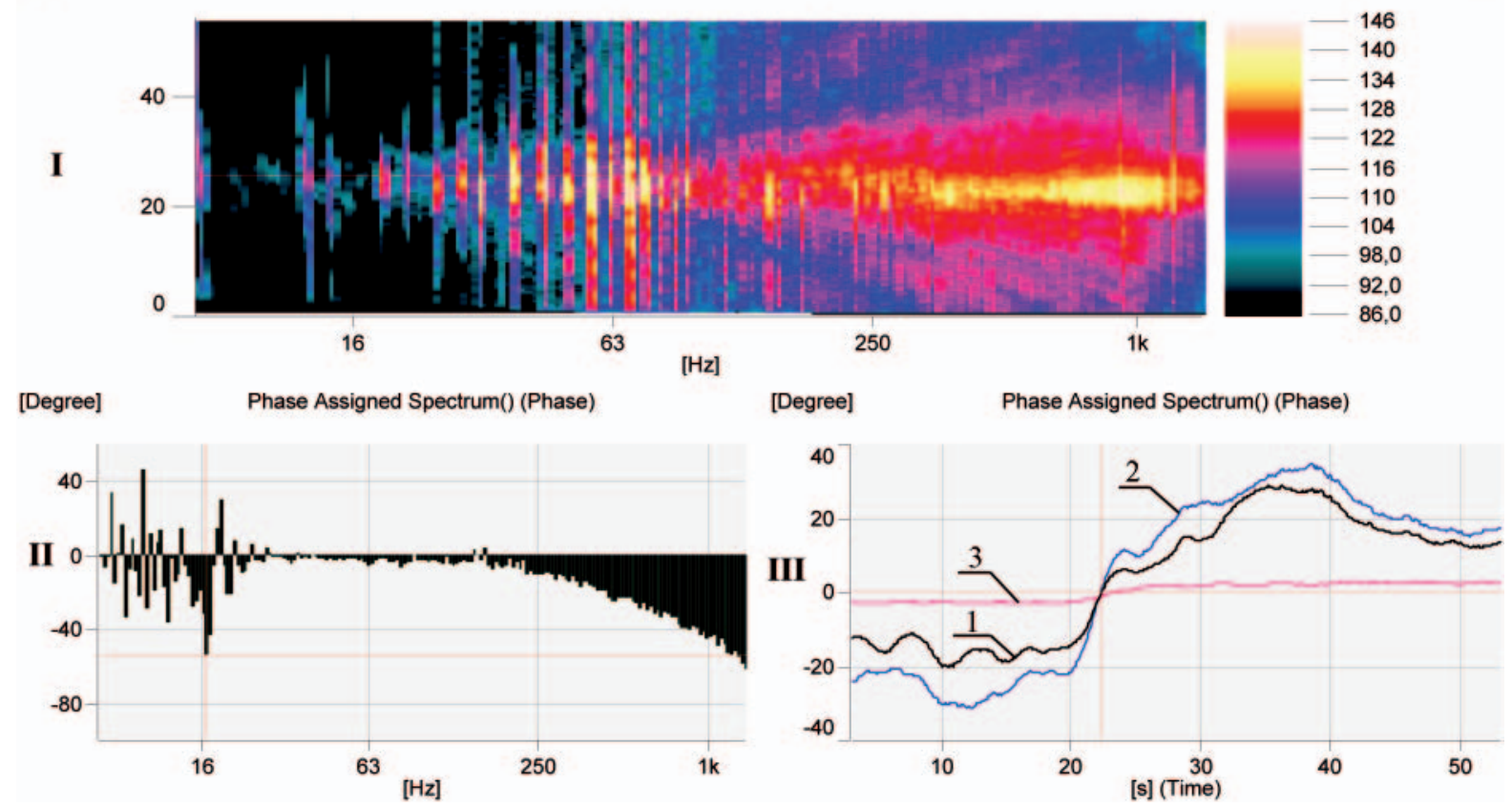

Fig. 18. I - the spectrogram of phase amplitude of underwater noise, $\boldsymbol{I I}$ - the spectrum of phases of underwater noise, III - the spectrum of noise phases calculated for the selected frequency bands: 1 - that from 6.9 [Hz] to $1.334[\mathrm{kHz}], 2$ - that from 100 [Hz] to $1.334[\mathrm{kHz}], 3$ - that from 6.9 [Hz] to 100 [Hz]

during approaching the trial area by the ship to, at $\mathrm{t}=23[\mathrm{~s}]$, the phase sign was negative, and behind the area - positive.

By comparing the spectra of sound intensity and signal phases it can be observed that during approaching the probe by the ship the sound intensity level obtains positive value and the phase - negative. The obtained positive values of sound intensity do not require any comments. The phenomenon is precisely described in many literature sources $[1,2,4,5,6]$.

The auxiliary Fig. 19 can be used to explain how to use sign value for a more accurate location of sound sources.

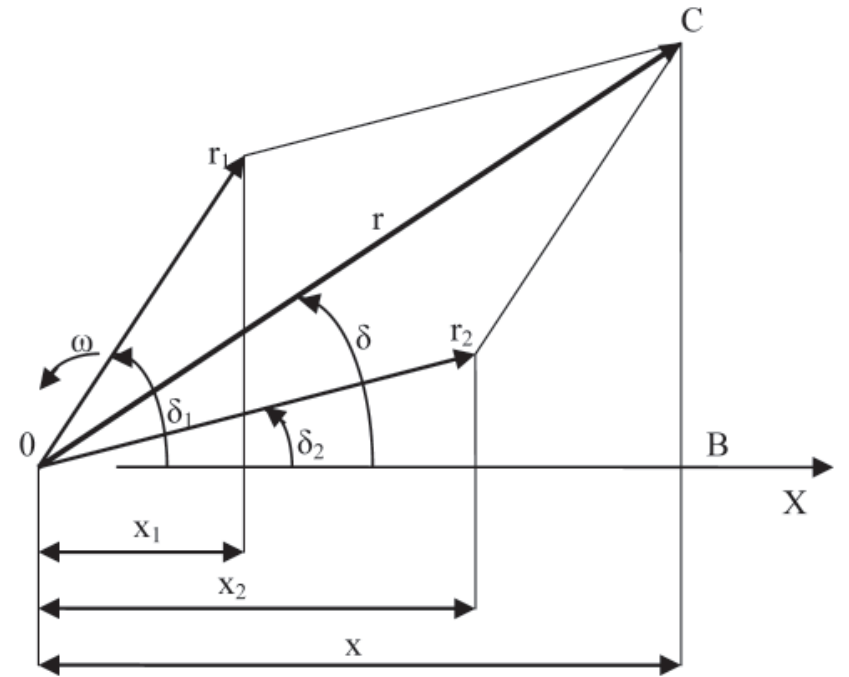

Fig. 19. Summation of vectors of waves of different amplitudes and initial phases. Notation: $x_{1}$-the deflection of the active component of the sound field wave amplitude $r_{\text {, }}$, initial phases $\delta$ and angular velocity $\omega$,

$\boldsymbol{x}_{2}$ - the deflection of the passive component of the sound field wave amplitude $r_{2}$, initial phases $\delta$, and angular velocity $\omega$, $\boldsymbol{x}$ - the deflection of wave resulted from summation of component vectors of active and passive sound field

From Fig. 19 we can easily determine the phase of the signal by using the dependence:

$$
\operatorname{tg} \delta=\frac{B C}{0 B}=\frac{r_{1} \sin \delta_{1}+r_{2} \sin \delta_{2}}{r_{1} \cos \delta_{1}+r_{2} \cos \delta_{2}}
$$

From principles of trigonometry it is known that tangent function takes positive values in the 1 st and 3rd quadrant, and negative - in the 2 nd and 4 th one.

Based on the knowledge of sign of sound intensity level and signal phase, a sound source can be located in an appropriate quadrant determined by the coordinates of sensor probe. The pictorial scheme of the location of the sound source in the relevant quadrant determined by pair of acoustic sensors, is shown in Fig. 20.

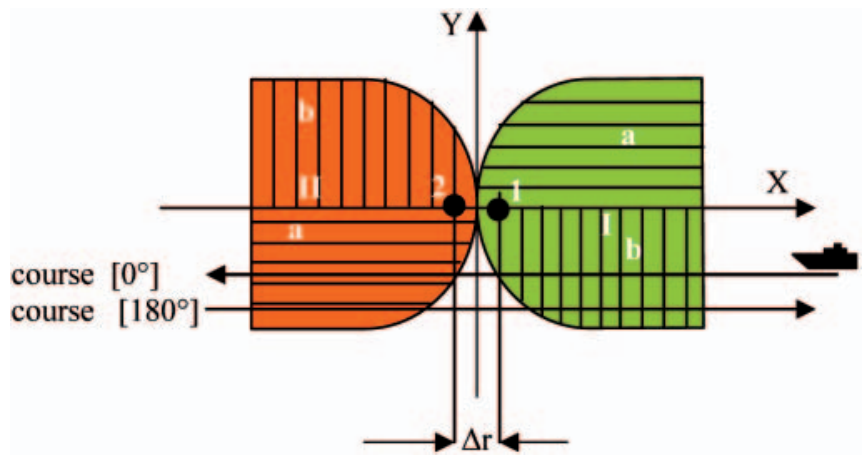

Fig. 20. The location of ship in the relevant quadrant determined by the sensor probe coordinates, during ship's passage trough trial area. Notation: I - the area of positive values of sound intensity level,

$\boldsymbol{I I}$ - the area of negative values of sound intensity level,

$\boldsymbol{a}$ - the quadrant of positive values of the sound field phase, $\boldsymbol{b}$ - the quadrant of negative values of the sound field phase,

$$
\text { 1, } 2 \text { - the hydroacoustic sensors }
$$

After the measurements carried out for the course of $0\left[^{\circ}\right]$ relative to the location of probe acoustic sensors, the measurements for the course of $180\left[^{\circ}\right]$ were performed. During the measurements the ship did not changed the area covered by the tests, against the location of the sensors axis, as shown in Fig. 18. From the tests the spectrogram of underwater noise intensity and spectrum of sound intensity in function of duration time of ship passage through the trial area, were achieved. In the spectrum it is clearly visible that when the ship approaches the probe (up to $t=43[\mathrm{~s}]$ ) sound pressure levels take negative values, and positive ones during the ship's departure from it. From comparison of the results of the measurements taken for 
the course of $0\left[^{\circ}\right]$ and $180\left[^{\circ}\right]$, the difference in signs of the sound intensity level and phase during approaching the probe by the ship and departing from it, is clearly visible.

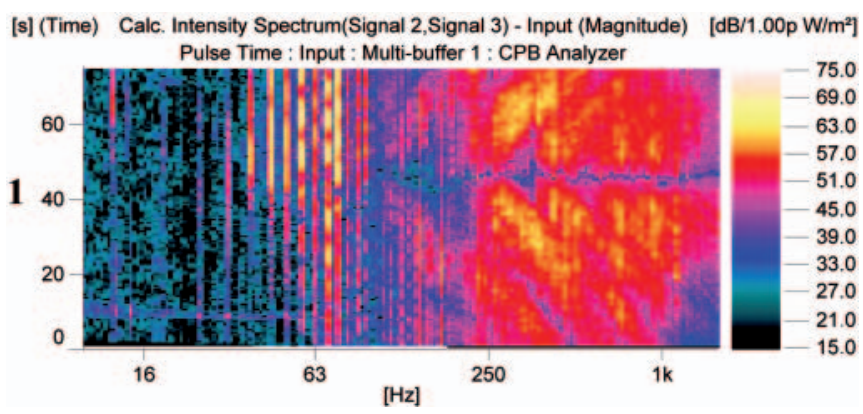

Fig. 21. The spectrogram of underwater noise intensity recorded in the frequency band from $6,9[\mathrm{~Hz}]$ to $1.334[\mathrm{kHz}]$

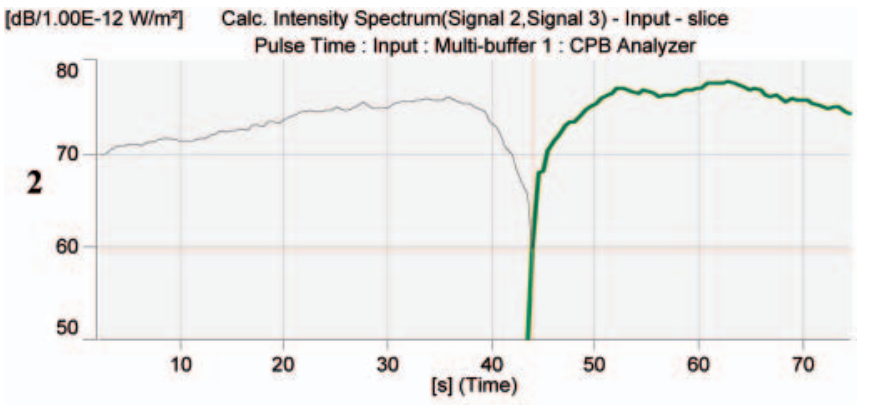

Cursor Values

$Y=59.4 \mathrm{~dB} / 1.00 \mathrm{E}-12 \mathrm{~W} / \mathrm{m}^{2} \quad 2006-04-20$ 11:14:01.280 Freq. Band Slice 1 (Sum) $X=774.821 \mathrm{~Hz}$

$Z=43.86 \mathrm{~s}$
Start $=9.71628 \mathrm{~Hz}$ Stop $=1.53993 \mathrm{k} \mathrm{Hz}$

Fig. 22. The analysis of the real part of complex spectrum of sound intensity, performed in the frequency band from $6.9[\mathrm{~Hz}]$ to $1.33[\mathrm{kHz}]$

On determination of the sound intensity, the determining of signal phases whose results are presented in Fig. 23 and 24, has been started.

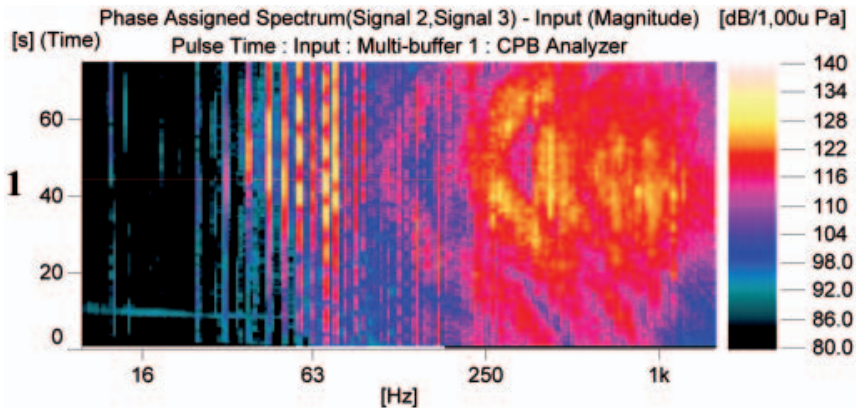

Fig. 23. The phase amplitude spectrogram of underwater noise, recorded in the frequency band from $6.9[\mathrm{~Hz}]$ to $1.334[\mathrm{kHz}]$

[Degree] Phase Assigned Spectrum(Signal 2,Signal 3) - Input - slice (Phase)
Pulse Time : Input : Multi-buffer 1: CPB Analyzer

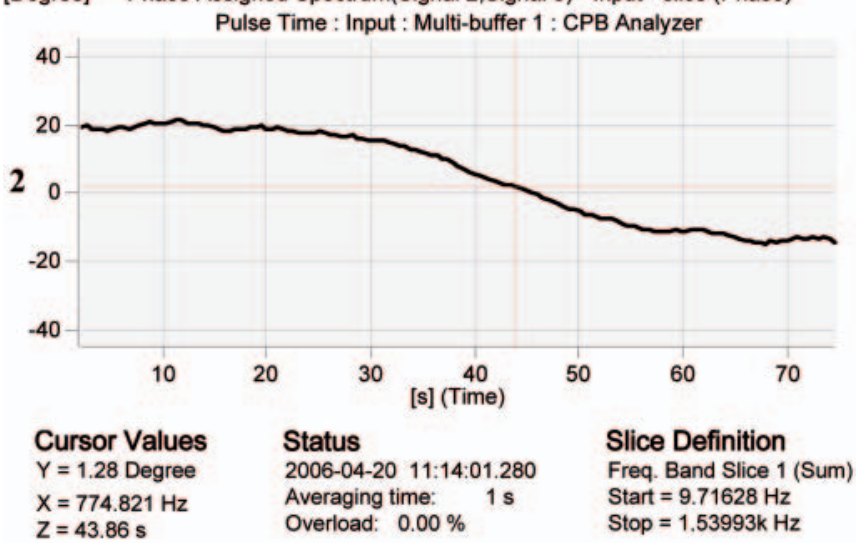

Fig. 24. The spectra of phase amplitude signals of underwater noise recorded in the frequency band from $6.9[\mathrm{~Hz}]$ to $1.334[\mathrm{kHz}]$

Comparing the results of phase measurements carried out for the tested courses, one obtained also the difference in signs, which confirms that to determine ship's course relative to sensors is possible.

\section{CONCLUSIONS}

The results of the performed research have demonstrated that by testing the sign of the sound intensity level and phase of noise signals it is possible to locate sound source just in a relevant quadrant determined by the sensor probe coordinates. To achieve a better accuracy is possible by increasing the number of pairs of sensors and spacing them properly. The use of three sensors located in an equilateral triangle will make it possible to reduce the sector of sound source location to $30\left[^{\circ}\right]$.

As demonstrated in the paper, the probe applied to measuring the sound intensity will make it possible to supplement the so far collected results of underwater noise investigations carried out in shallow waters by knowledge on direction of propagation of hydroacoustic waves.

On the basis of known values of sound pressure and intensity it is possible to elaborate the following characteristics:

a) the noise spectral structures of vessels,

b) the results of vibration of mechanisms and equipment installed on ships, which greatly affect spectral structure of ship acoustic field (main engines, generators, shaft lines, screw propeller),

c) the results of research on the relationship between ship underwater noise and vibration of ship mechanisms,

d) initial assessment of technical state of ship machinery,

e) estimation of the energy transmission coefficient,

f) the measurement results of sound pressure level changes in function of ship's forward speed,

g) the results of sound pressure level changes in function of distance,

h) presentation of the acoustic wave propagation model made for water depth values selected along ship's trajectory,

i) determination of direction of propagation of hydroacoustic waves.

This paper has an experimental character and constitutes a continuation of many other investigations in the subjectmatter area $[7 \div 18]$.

In the future a series of extensive studies should be conducted, on the basis of which the maximum distance from which to identify and locate particular vessels is still possible, could be determined. The investigations should be performed in the coastal zone, at different sea states and different levels of hydroacoustic background noise, as well as in the trial areas located in the Gdansk Bay, at different water depths.

\section{BIBLIOGRAPHY}

1. Kozaczka E., Grelowska G., Bittner P., Baranowska A., Milanowski W., Dobrzaniecki J.: Spatial distribution of underwater noises radiated by ship to hemisphere and its standardization Gdynia 1997

2. Kozaczka E., Grelowska G., Gloza I., Dobrzaniecki J.: Determination of phase displacement of hydrophone. Control measurements in a test tank and at sea, Hydroacoustics, Volume 3, Gdynia 2000

3. Bulletin of Brüel \&Kjar, 1973

4. Elliots S.J.: Errors in Acoustic Intensity Measurements. Journal of Sound and Vibration 1982

5. Thompson J.K.\& Tree D. R.: Finite difference approximation errors in acoustic intensity measurements. Journal of Sound and Vibration 1981 
6. Jacobson F.: Measurement of sound intensity. Acoustics Laboratory of the Danish Technical University.

7. Kozaczka E., Grelowska G., Bittner P., Baranowska A., Kiciński W., Milanowski W.: Spatial distribution of underwater noise radiated by ship to hemisphere. STAGE II, Proceedings of 9th Symposium on Hydroacoustics, Gdynia 1992

8. Baranowska A., Gloza I.: Identification of underwater disturbance sources with using the coherence function. Proceedings of 48th Open Seminar on Acoustics, Wroclaw 2001

9. Dobrzaniecki., Gloza I., Domagalski J.: Preliminary research on monitoring the own ship noise, Proceedings of 50th Open Seminar on Acoustics, Szczyrk - Gliwice 2003.

10.Gloza I.: The investigation of changes of ships underwater noise in shallow sea, Doctoral thesis, Polish Naval Academy, Gdynia 1994

11. Gloza I.: Experimental research of noise generated by ship's engine, Proceedings of 6th Symposium on Hydroacoustics, Gdynia 1989

12.Gloza I.: Assessment of technical state of ships propulsion system on the basis of measurement of hydroacoustic noise. Proceedings of 10th Symposium on Hydroacoustics, Gdynia 1993

13.Gloza I., Malinowski S.: Identification of ships underwater noise sources in the coastal region. Hydroacoustics, Vol. 5/6, 2003

14.Gloza I., Domagalski J.: The investigation of propagation of acoustic waves generated by moving ship. Hydroacoustics, Vol. $5 / 6,2003$

15.Gloza I., Domagalski J., Malinowski S.: The character of underwater noise radiated by small vessels. Hydroacoustics, Vol. 4, 2001.
16.Gloza I., Domagalski J., Malinowski S.: Identification of ships underwater noise sources in near field. Proceedings of 49th Open Seminar on Acoustics, Warszawa - Stare Jablonki 2002

17.Gloza I., Domagalski J., Dobrzaniecki J.: The structure of acoustics field of vessel's underwater noise in near field. Proceedings of 48th Open Seminar on Acoustics, Wroclaw 2001

18. Grelowska G., Bittner P.: The processing of underwater signals produced by ship with the possibility of increasing the frequency resolution. Scientific Bulletin of Polish Naval Academy, vol. XXXIV, 4, 1994.

\section{CONTACT WITH THE AUTHORS}

Eugeniusz Kozaczka, Prof., Faculty of Ocean Engineering and Ship Technology

Gdansk University of Technology Narutowicza 11/12

80-233 Gdansk, POLAND fax: (058) 347-21-81, e-mail: kozaczka@pg.gda.pl

Jacek Domagalski, Ph. D. Ignacy Gloza, $\mathrm{Ph}$. D.

Faculty of Navigation and Naval Waeapons,

Polish Naval Academy

Śmidowicza 69

81-103 Gdynia POLAND

e-mail: i.gloza@amw.gdynia.pl 